\title{
Diffusion of methane and other alkanes in metal-organic frameworks for natural gas storage
}

\author{
Bhaskarjyoti Borah, Hongda Zhang, and Randall Q Snurr* \\ Chemical \& Biological Engineering Department, \\ Northwestern University, Evanston, IL 60208, USA
}

*Corresponding author: snurr@northwestern.edu

\begin{abstract}
Diffusion of methane, ethane, propane and n-butane was studied within the micropores of several metal-organic frameworks (MOFs) of varying topologies, including the MOFs PCN-14, NU-125, NU-1100 and DUT-49. Diffusion coefficients of the pure components, as well as methane/ethane, methane/propane and methane/butane binary mixtures, were calculated using molecular dynamics simulations to understand the effect of the longer alkanes on uptake of natural gas in MOFs. The calculated self-diffusion coefficients of all four components are on the order of $10^{-8} \mathrm{~m}^{2} / \mathrm{s}$. The diffusion coefficients of the pure components decrease as a function of chain length in all of the MOFs studied and show different behaviour as a function of loading in different MOFs. The self-diffusivities follow the trend $\mathrm{D}_{\mathrm{PCN}-14}<\mathrm{D}_{\mathrm{NU}-125} \approx \mathrm{D}_{\mathrm{NU}-1100}<\mathrm{D}_{\mathrm{DUT}-49}$, which is exactly the reverse order of the densities of the MOFs: PCN-14 $>$ NU-125 $\approx$ NU-1100 $>$ DUT-49. By comparing the diffusion of pure methane and methane mixtures with the higher alkanes, it is observed that the diffusivity of methane is unaffected by the presence of the higher alkanes in the MOFs considered, indicating that the diffusion path of methane is not blocked by the higher alkanes present in natural gas.
\end{abstract}

Keywords: molecular simulation; molecular dynamics; MOF; adsorption; diffusivity 


\section{Introduction}

Continued burning of fossil fuels is leading to an alarming increase in the level of $\mathrm{CO}_{2}$ in the earth's atmosphere. Since transportation accounts for $\sim 30 \%$ of $\mathrm{CO}_{2}$ emissions worldwide, alternate vehicle fuels could play an important role in reducing global $\mathrm{CO}_{2}$ emissions. Natural gas is a promising automobile fuel, which burns more cleanly than petroleum and has lower $\mathrm{CO}_{2}$ emissions. In current natural gas vehicles, the gas is compressed to pressures as high as 250 bar. In recent years, researchers have searched for adsorbents that would allow storage of methane (the major component of natural gas) at much lower pressure. Among the most promising materials are metal-organic frameworks (MOFs) (Férey, 2008; Horike et al., 2009; Long and Yaghi, 2009; O'Keeffe et al., 2008; Rowsell and Yaghi, 2004) due to their large internal surface areas (Düren et al., 2004; Eddaoudi et al., 2002; Ma et al., 2008; Ma and Zhou, 2010; Morris and Wheatley, 2008; Peng et al., 2013; Zhou et al., 2009). Because of their modular assembly from organic linkers and metal clusters, there are an almost unlimited number of MOFs, and researchers have synthesized many promising MOFs for storing methane (Mason et al., 2014; Peng et al., 2013; Senkovska and Kaskel, 2008; Stoeck et al., 2012; Wu et al., 2010; Zhou et al., 2009).

In an early demonstration of methane storage, Kitagawa and co-workers (Kondo et al., 1997) reported a significant uptake of $52 \mathrm{~cm}^{3}$ (STP)/g at $298 \mathrm{~K}$ and 30 bar in a coordination polymer $\left[\mathrm{Co}_{2}(4,4 \mathrm{bpy})_{3}\left(\mathrm{NO}_{3}\right)_{4} \cdot 4 \mathrm{H}_{2} \mathrm{O}\right]_{\mathrm{n}}$. Following this initial work, there has been enormous development. Yaghi and his group reported methane uptake in a series of isoreticular MOFs and found one of the members showing high storage capacity of $240 \mathrm{~cm}^{3}$ (STP)/g at $298 \mathrm{~K}$ and 36 bar (Eddaoudi et al., 2002). This was a significant improvement compared to Kitagawa's initial findings and was a motivation for more researchers to explore methane storage in MOFs. Senkovska and Kaskel (2008) studied methane adsorption in the MOF HKUST-1, which was originally synthesized by Chui et al. (1999), and reported uptake of 
methane at $298 \mathrm{~K}$ and 35 bar of $160 \mathrm{~cm}^{3}(\mathrm{STP}) / \mathrm{cm}^{3}$. Férey and his group studied methane adsorption in MIL-53-Cr and reported an uptake of $165 \mathrm{~cm}^{3}$ (STP)/ $/ \mathrm{cm}^{3}$ at $303 \mathrm{~K}$ and $35 \mathrm{bar}$ (Bourrelly et al., 2005; Millange et al., 2002).

Inspired by a suggestion from computational modelling (Düren et al., 2004), Zhou's group reported the MOF PCN-14 and investigated its methane storage potential (Ma et al., 2008). They reported excess methane uptake of $220 \mathrm{~cm}^{3}(\mathrm{STP}) / \mathrm{cm}^{3}$ at $290 \mathrm{~K}$ and $35 \mathrm{bar}$. This exceptionally high uptake set a record for methane storage. The same group also reported another MOF with the same topology, PCN-11 (Wang et al., 2008), which exhibits reasonably good methane uptake of $171 \mathrm{~cm}^{3}(\mathrm{STP}) / \mathrm{cm}^{3}$ at $298 \mathrm{~K}$ and 35 bar. Wu et al. (2009) and Dietzel et al. (2009) discovered that Ni-MOF-74 has methane uptake of $190 \mathrm{~cm}^{3}(\mathrm{STP}) / \mathrm{cm}^{3}$ at $298 \mathrm{~K}$ and 35 bar. Recently, Wilmer et al. (2013) reported another new structure called NU-125 and measured an absolute methane storage capacity of $228 \mathrm{~cm}^{3}(\mathrm{STP}) / \mathrm{cm}^{3}$ at $298 \mathrm{~K}$ and $58 \mathrm{bar}$.

It should be noted that the total amount of methane stored in the MOF is only useful if most of the methane can be recovered upon lowering the pressure. Therefore, another important metric is the so-called deliverable capacity, which is defined as the amount of methane stored at the storage pressure minus the amount stored at the delivery pressure. For example, the methane deliverable capacity of NU-125 between 65 bar and 5.8 bar is $174 \mathrm{~cm}^{3}$ (STP) $/ \mathrm{cm}^{3}$ at 298 K. Recently, Peng et al. (2013) and Mason et al. (2014) have established that HKUST-1 is the best candidate among all MOFs, with a methane deliverable capacity of $150 \mathrm{~cm}^{3}(\mathrm{STP}) / \mathrm{cm}^{3}$ between 35 bar and 5 bar. They have summarized the new record holding MOFs for methane storage. According to them, the MOFs NU-111, NU-125, UTSA-20, PCN-14, NiMOF-74, MOF-5, and HKUST-1 are some of the best candidates for storing and delivering methane.

Natural gas contains methane $(\sim 90-95 \%)$, ethane $(\sim 2.5 \%)$, propane $(\sim 0.2 \%)$, butane $(\sim 0.03 \%), \mathrm{N}_{2}(\sim 0.2-5.5 \%), \mathrm{CO}_{2}(\sim 0.1 \%)$ and other trace gases. The presence of the longer 
alkane molecules (ethane, propane and butane) can create challenges in storing and delivering methane because these alkanes might block the diffusion path of methane within the pores of the MOF. Therefore, it is important to explore and understand the diffusion behaviour of methane in the presence of the higher alkanes.

In the literature, there are several previous reports on diffusion of alkanes in various MOFs. Sarkisov et al. (2004) reported the self-diffusivities in MOF-5 (also known as IRMOF-1) of various hydrocarbons including $n-C_{5}$ to $n-C_{7}$ from molecular dynamics (MD) simulations almost 2 years before the first experimental studies of diffusion in MOFs (Stallmach et al., 2006). Ford et al. (2012) reported a combined simulation and experimental study of hydrocarbon diffusion in IRMOF-1 and found excellent agreement between results from MD and from PFG NMR measurements. The self-diffusion coefficients for this system are of same order of magnitude as those in bulk liquids. Diffusion of alkane isomer mixtures of $\mathrm{C}_{4}$ and $\mathrm{C}_{5}$ in IRMOF-13, IRMOF-14, PCN-6 and PCN-6' was studied by Babarao et al. (2009). They concluded that diffusion coefficients of alkanes in these MOFs decrease with the degree of branching. They also observed that the diffusion selectivity is larger in IRMOF-13 and PCN-6, which are catenated and have smaller pores, than in IRMOF-14 and PCN-6', which are noncatenated. Chmelik et al. (2009) performed infra-red microscopy and molecular simulations to investigate diffusion and adsorption of n-butane, iso-butane, 2-methylbutane and 2,2-dimethyl propane in HKUST-1. Their findings indicate that the isotherm inflection has a significant influence on the Maxwell-Stefan diffusivity. NMR experiments were performed by Stallmach et al. (2006) to explore the diffusion of hydrocarbons in MOF-5. They investigated diffusion of methane, ethane, n-hexane, and benzene and found high mobility of these molecules within the pores of MOF-5. Rives et al. (2012) combined neutron scattering experiments with MD simulations to study diffusion of long chain n-alkanes in MIL-47(V). Their experimental diffusivities show non-monotonically 
decreasing behaviour with increasing chain length, while the MD simulations confirmed that diffusion occurs through jump sequences as suggested by the experiments. In another study of diffusion of n-alkanes in MIL-47(V), Jobic et al. (2010) found that n-butane shows higher diffusivity at low loadings than propane, which they referred to as a blowgun effect.

In the present study, we have conducted molecular dynamics (MD) simulations to predict the diffusion behaviour of pure methane, ethane, propane and butane as well as binary mixtures of methane/ethane, methane/propane and methane/butane in a few topologically varying MOFs with a range of pore sizes. We have chosen six MOFs that appear promising for natural gas storage, namely, PCN-14 (Ma et al., 2008), NU-125 (Wilmer et al., 2013), DUT-49 (Stoeck et al., 2012), NU-1100 (Gutov et al., in press), and two hypothetical MOFs, Py-4PT-ftw and Py-4TT-ftw.

PCN-14 belongs to the nbo topology. This MOF crystallizes in rhombohedral crystal symmetry and belongs to the space group $R 3 c$. The secondary building units (SBU) of this MOF are a copper paddlewheel as the metal node and 5, 5'- $(9,10$ -anthracenediyl)di-isophthalate as the organic linker. Figure 1 shows the two SBUs and the structure of PCN-14. NU-125 has an rht topology and belongs to the space group $I 4 / \mathrm{m}$. It contains four different cages. The SBUs and structure of NU-125 are shown in Figure 2. This MOF is an assembly of copper paddlewheels and hexa-carboxylate struts (Wilmer et al., 2013). DUT-49 is a cubic crystal. It belongs to the space group Fm-3m. This MOF has an fcu topology. The SBUs and structure of this MOF are shown in Figure 3. NU-1100 belongs to the ftw topology (Gutov et al., in press). It is a cubic crystal. The SBUs and structure of this MOF are shown in Figure 4. Py-4PT-ftw and Py-4TT-ftw are hypothetical variations of NU-1100 with different organic linkers shown in Figure 5. Both Py-4PT-ftw and Py-4TT-ftw are orthorhombic but not exactly cubic. 


\section{Computational Details}

We performed molecular dynamics simulations of pure methane, ethane, propane and butane and also binary mixtures of methane/ethane, methane/propane and methane/butane in the MOFs described above. The simulations were carried out at $298 \mathrm{~K}$. Each system was equilibrated for $2 \mathrm{~ns}$, and then a further 2 ns run was made during which the positions and velocities of the atoms were stored at an interval of $1 \mathrm{ps}$. Newton's equations of motion were solved using the velocity Verlet scheme with an integration time step of 1 fs. We employed the usual periodic boundary conditions along all three directions. All simulations were conducted using the LAMMPS package (Plimpton, 1995).

The adsorbate-adsorbate and adsorbate-framework interactions were modelled with the well known Lennard-Jones potential, with a cutoff distance of $14 \AA$. The Lennard-Jones parameters for the framework atoms were taken from the Dreiding force field (Mayo et al., 1990), and the adsorbate molecules were modelled with the TraPPE force field (Martin and Siepmann, 1998). The united atom approach was used to model the adsorbate molecules. Methane was modelled as a single spherical center. Similarly, $\mathrm{CH}_{3}$ and $\mathrm{CH}_{2}$ were modelled as single spherical beads. All intramolecular motions (bond stretching, bond angle bending and torsional motions) of the adsorbate molecules were included, making them flexible. The MOF atoms were considered frozen at their crystallographic coordinates. The flexibility of the MOF is important mainly when the size of the adsorbate is comparable to the pore-limiting diameter of the framework (Haldoupis et al., 2012). In large-pore materials, the influence of framework flexibility on diffusion is insignificant (Amirjalayer et al., 2006; Ford et al., 2009; Haldoupis et al., 2012). In our case, the frameworks are relatively open and, with the exception of $\mathrm{PCN}-14$, have pore-limiting diameters significantly larger than the adsorbates, justifying the assumption of rigid frameworks in this study. Future work checking the validity of this assumption for PCN-14 would be useful. 
The mean square displacements (MSD) of the molecules were computed using the calculated coordinates during the production run. Least squares fitting was performed to get the slope of the MSDs, and self-diffusion coefficients were then computed using the Einstein relation (Dubbeldam and Snurr, 2007). Throughout the rest of the article, the terms diffusion coefficient and diffusivity refer to the self-diffusion coefficient.

\section{Results and Discussion}

\subsection{Computational Characterization of the MOFs}

The pore size distributions of the MOFs were calculated using the method described by Gelb and Gubbins (1999). These are shown in Figure 6. The distributions show pronounced peaks indicating well defined pores in these MOFs. For example, NU-125 has four peaks in the pore size distributions, corresponding to four different cavities (Wilmer et al., 2013). DUT-49, Py-4PT-ftw and Py-4TT-ftw have three distinct pores, and PCN-14 and NU-1100 have two pores each.

We also computed other properties such as the largest cavity diameter (LCD) and pore limiting diameter (PLD) of these MOFs using the Poreblazer program (Sarkisov and Harrison, 2011). The LCDs and PLDs along with the framework densities of the MOFs are listed in Table 1. It is clearly observed that DUT-49 is a quite open structure, having the highest LCD and PLD, as well as the lowest density among the six MOFs considered. On the other hand, PCN-14 contains the smallest LCD and PLD values and has the highest framework density. The density of these MOFs follows the trend PCN-14 $>$ NU-125 $\approx$ Py-4TT-ftw $>$ Py-4PT-ftw $>$ DUT-49.

\subsection{Pure Component Diffusion}

Diffusion coefficients in microporous solids show different behaviour as a function of loading. $\mathrm{K}$ rger and Pfeifer identified five different types of behaviour that self-diffusion 
coefficients show in a variety of microporous solids (Kärger and Pfeifer, 1987), shown schematically in Figure S6. Depending upon the pore size, pore topology and presence of extra-framework cations, the diffusion coefficients follow different profiles as a function of loading. The type I behaviour is commonly seen and is due to steric hindrance. The other types of diffusion behaviours are specific to particular systems.

We computed the diffusion coefficients of pure methane, ethane, propane and butane in all six MOFs considered in this study as a function of loading. The mean square displacements are shown in Figures S3, S4 and S5. The MSDs are straight and linear with respect to time indicating good statistics. The diffusion coefficients obtained from the MSDs are shown in Figures 7 and 8. The error bars are less than or equal to $10 \%$. In Figure 7, it is clearly seen that the diffusion coefficients of all four molecules follow type I behaviour for PCN-14, NU-1100, Py-4PT-ftw, and Py-4TT-ftw. The diffusivities decrease monotonically as a function of loading. This is due to increasing steric hindrance when the loading is increased. On the other hand, as shown in Figure 8, the diffusivities of methane and ethane show type II behaviour, and propane and butane show type IV behaviour in DUT-49 and NU-125. In the case of methane and ethane, the diffusivities are more or less flat at low loadings and then start to decrease as loading increases. This kind of behaviour was previously observed for ethene, but-1-ene and many aromatic compounds in zeolites such as $\mathrm{NaX}$ (Germanus et al., 1984; Germanus et al., 1985). Germanus and co-workers attributed this to the presence of extra-framework cations. Interestingly, we see this type of behaviour even in MOFs without any extra-framework ions. In case of propane and butane, the diffusivity increases as a function of loading, reaches a maximum, and then decreases as loading is further increased. This type IV behaviour has been observed in various other porous solids such as zeolites (LTA, CHA, DDR and ERI) (Krishna and van Baten, 2008) and MOFs (HKUST-1) (Babarao et al., 2009; Chmelik et al., 2009). 
Experimental diffusion results are not available for the systems in Figures 7 and 8, but Jobic et al. (2010) have conducted quasi-elastic neutron scattering experiments and molecular dynamics simulations to obtain the diffusion behaviour of ethane, propane, and butane in MIL-47(V). The magnitudes of the diffusion coefficients obtained by Jobic are of the same order as those reported in Figures 7 and 8. Jobic et al. also studied the loading dependence of the diffusion coefficients and observed Type I behaviour for all three alkanes. In another MOF, MIL-53(Cr), Rosenbach et al. (Rosenbach et al., 2014) also observed Type I behaviour for ethane, propane, and butane.

In order to explain the initial increase and then decrease in diffusivity, we looked at the siting of propane and butane in DUT-49 and NU-125. There are three and four different cages in DUT-49 and NU-125, respectively, as shown in Figure 9. We will refer to these as Cage 1, Cage 2, etc., with Cage 1 being the smallest. The diameter of the smallest cage in NU-125 is $\sim 7.3 \AA$ and that in DUT-49 is $\sim 11 \AA$. Figure 10 shows the average number of propane molecules in NU-125 and DUT-49 for the different cages. At low loadings, most molecules are in the smallest cage, and the bigger cages are mostly empty. As the loading is increased, the bigger cages start filling up. Similar siting behaviour is also seen for butane in NU-125 and DUT-49. With the help of this siting information, we can explain the type IV behaviour of propane and butane in NU-125 and DUT-49. At low loadings the adsorbate prefers to be in the smaller pores, which display the most favourable adsorption energies. Therefore, it is more bound to the surface at low loadings and is less mobile. As the loading of molecules increases, molecules start occupying the bigger pores where their motion is more facile, and hence the diffusivity increases. Even further increase of loading makes the pores more crowded, steric hindrance comes into play, and the diffusivity decreases as a function of loading. It is clearly observed that the diffusion behaviour as a function of loading can be 
widely different depending upon the properties of the MOF (or in general microporous solid) such as topology, pore structure, pore size and the kind of adsorbate.

Another point to be noted is that in all six MOFs the diffusion coefficients follow the order methane $>$ ethane $>$ propane $>$ butane. Methane diffuses fastest in all of these MOFs due to its low mass and smaller size, whereas diffusion coefficients decrease as the chain length is increased due to increase in mass and size. In the present study, we do not see any anomalies in diffusivity as a function of chain length.

\subsection{Mixture Diffusion}

We also investigated the effect of presence of the impurities, ethane, propane, and butane, on the diffusion of methane. In the context of natural gas storage, we wanted to know if the presence of these impurity components would significantly affect the diffusion of methane, thus affecting the ability to release methane from the adsorbent. We considered binary mixtures of $90 \%$ methane and $10 \%$ other alkanes, roughly reflecting the typical composition of natural gas. Molecular dynamics simulations were conducted on these mixtures keeping the total fractional loading $\left(\theta / \theta_{0}\right.$, where $\theta_{0}$ is the saturation loading) at 0.63 . The diffusion coefficients of methane in binary mixtures with ethane, propane and butane are compared with diffusion of pure methane in Figure 11. It is clear that the diffusion of methane is not significantly affected by the presence of any of the impurity components, suggesting that the longer alkanes do not block the diffusion path of methane in any of the MOFs studied. It is also worth looking at the diffusivities of the impurities when they are in the mixture with methane versus when they are pure. As shown in Figure 12, the diffusivities of the impurities are not significantly affected by methane. There are some minor increases or decreases due to the presence of methane, but the effects are insignificant.

From Figures 11 and 12, it is clear that the presence of longer alkanes does not affect the diffusion of methane (or vice versa) in these promising MOFs for natural gas storage. In 
addition, we see that the diffusion coefficients of methane in the MOFs considered here are fast and have a similar order of magnitude as diffusion in liquids. Using the diffusion coefficients of methane within these MOF materials, we performed a simple calculation to estimate the time for a methane molecule to travel through a particle of size $1 \mu \mathrm{m}$. From the Einstein equation, the average time to move a root mean square distance of $1 \mu \mathrm{m}$ is of the order of a few tens of milliseconds.

\section{Conclusions}

The diffusion behaviour of pure methane, ethane, propane, and butane, as well as binary mixtures of methane/ethane, methane/propane, and methane/butane, was investigated in six promising MOFs for natural gas storage. The diffusion coefficients of the pure components show different behaviour as a function of loading in the different MOFs. All components show type I behaviour in PCN-14, NU-1100, Py-4PT-ftw and Py-4TT-ftw. On the other hand, methane and ethane show type II behaviour and propane and butane show type IV behaviour in DUT-49 and NU-125. The diffusion behaviour depends upon the topology, pore structure, and pore size of the MOF. The diffusion coefficients, however, correlate well with the density, the pore limiting diameter, and the openness of the MOFs. Diffusion coefficients are smallest in the case of the densest MOF, PCN-14, and largest in the least dense MOF, DUT-49. Moreover, diffusivities are seen to be largest for methane and gradually decrease as the chain length increases. Diffusion coefficients of pure methane and mixtures of methane with ethane, propane, or butane were compared, and it is clearly seen that the methane diffusivities are not affected by the presence of the higher alkanes in the six MOFs examined. Overall, the diffusivities are on the order of $10^{-8} \mathrm{~m}^{2} / \mathrm{s}$, and intracrystalline diffusion should not be a problem for natural gas tanks containing any of these MOF adsorbents. 


\section{Acknowledgement}

The work presented herein was funded by the Advanced Research Projects Agency-Energy (ARPA-E), U.S. Department of Energy, under Award Number DE-AR0000248.

\section{References}

Amirjalayer, S., Tafipolsky, M., Schmid, R., 2006. Molecular Dynamics Simulation of Benzene Diffusion in MOF-5: Importance of Lattice Dynamics. Angewandte Chemie-International Edition 46, 463-466.

Babarao, R., Tong, Y.H., Jiang, J., 2009. Molecular Insight into Adsorption and Diffusion of Alkane Isomer Mixtures in Metal-Organic Frameworks. Journal of Physical Chemistry B 113, 9129-9136.

Bourrelly, S., Llewellyn, P.L., Serre, C., Millange, F., Loiseau, T., Férey, G., 2005. Different adsorption behaviors of methane and carbon dioxide in the isotypic nanoporous metal terephthalates MIL-53 and MIL-47. Journal of the American Chemical Society 127, 13519-13521.

Chmelik, C., Kärger, J., Wiebcke, M., Caro, J., van Baten, J.M., Krishna, R., 2009. Adsorption and diffusion of alkanes in CuBTC crystals investigated using infra-red microscopy and molecular simulations. Microporous and Mesoporous Materials 117, 22-32.

Chui, S.S.Y., Lo, S.M.F., Charmant, J.P.H., Orpen, A.G., Williams, I.D., 1999. A chemically functionalizable nanoporous material $\left[\mathrm{Cu}_{3}(\mathrm{TMA})_{2}\left(\mathrm{H}_{2} \mathrm{O}\right)_{3}\right]_{\mathrm{n}}$. Science $283,1148-1150$.

Dietzel, P.D.C., Besikiotis, V., Blom, R., 2009. Application of metal-organic frameworks with coordinatively unsaturated metal sites in storage and separation of methane and carbon dioxide. Journal of Materials Chemistry 19, 7362-7370.

Dubbeldam, D., Snurr, R.Q., 2007. Recent developments in the molecular modeling of diffusion in nanoporous materials. Molecular Simulation 33, 305-325.

Düren, T., Sarkisov, L., Yaghi, O.M., Snurr, R.Q., 2004. Design of new materials for methane storage. Langmuir 20, 2683-2689.

Eddaoudi, M., Kim, J., Rosi, N., Vodak, D., Wachter, J., O'Keeffe, M., Yaghi, O.M., 2002. Systematic design of pore size and functionality in isoreticular MOFs and their application in methane storage. Science 295, 469-472.

Férey, G., 2008. Hybrid porous solids: past, present, future. Chemical Society Reviews 37, 191-214.

Ford, D.C., Dubbeldam, D., Snurr, R.Q., 2009. The effect of framework flexibility on diffusion of small molecules in the metal-organic framework IRMOF-1. In Diffusion Fundamentals III; Chmelik, C., Kanellopoulos, N., Kärger, J., Theodorou, D., Eds. Leipziger 
Universitätsverlag: Leipzig, Germany, pp. 459-466.

Ford, D.C., Dubbeldam, D., Snurr, R.Q., Kunzel, V., Wehring, M., Stallmach, F., Karger, J., Muller, U., 2012. Self-Diffusion of Chain Molecules in the Metal-Organic Framework IRMOF-1: Simulation and Experiment. J. Phys. Chem. Lett 3, 930-933.

Gelb, L.D., Gubbins, K.E., 1999. Pore size distributions in porous glasses: A computer simulation study. Langmuir 15, 305-308.

Germanus, A., Kärger, J., Pfeifer, H., 1984. Self-diffusion of paraffins and olefins in zeolite $\mathrm{Na}-\mathrm{X}$ under the influence of residual water-molecules. Zeolites 4, 188-190.

Germanus, A., Kärger, J., Pfeifer, H., Samulevic, N.N., Zdanov, S.P., 1985. Intracrystalline self-diffusion of benzene, toluene and xylene isomers in zeolites Na-X. Zeolites 5, 91-95.

Gutov, O.V., Bury, W., Gomez-Gualdron, D.A., Krungleviciute, V., Fairen-Jimenez, D., Mondloch, J.E., Sarjeant, A.A., Al-Juaid, S.S., Snurr, R.Q., Hupp, J.T., Yildirim, T., Farha, O.K., in press. Water-stable zirconium-based metal-organic framework with high-surface-area and gas-storage capacities. Chemistry - A European Journal.

Haldoupis, E., Watanabe, T., Nair, S., Sholl, D.S., 2012. Quanitfying Large Effects of Framework Flexibility on Diffusion in MOFs: $\mathrm{CH}_{4}$ and $\mathrm{CO}_{2}$ in ZIF-8. ChemPhysChem 13, 3449-3452.

Horike, S., Shimomura, S., Kitagawa, S., 2009. Soft porous crystals. Nature Chemistry 1, 695-704.

Jobic, H., Riosenbach Jr, N., Ghoufi, A., Kolokolov, D., Yot, P.G., Devic, T., Serre, C., Ferey, G., Maurin, G., 2010. Unusual Chain-Length Dependance of the Diffusion of n-alkanes in the Metal-Orgnaics Framework MIL-47(V): The Blowgun Effect. Chemistry - A European Journal 16, 10337-10341.

Kärger, J., Pfeifer, H., 1987. NMR self-diffusion studies in zeolite science and technology. Zeolites 7, 90-107.

Kondo, M., Yoshitomi, T., Seki, K., Matsuzaka, H., Kitagawa, S., 1997. Three-dimensional framework with channeling cavities for small molecules: $\left\{\left[\mathrm{M}_{2}\left(4,4^{\prime}-\text { bpy }\right)_{3}\left(\mathrm{NO}_{3}\right)_{4}\right] \mathrm{xH}_{2} \mathrm{O}_{\mathrm{n}}(\mathrm{M}\right.$ $=\mathrm{Co}, \mathrm{Ni}, \mathrm{Zn})$. Angewandte Chemie-International Edition 36, 1725-1727.

Krishna, R., van Baten, J.M., 2008. Insights into diffusion of gases in zeolites gained from molecular dynamics simulations. Microporous and Mesoporous Materials 109, 91-108.

Long, J.R., Yaghi, O.M., 2009. The pervasive chemistry of metal-organic frameworks. Chemical Society Reviews 38, 1213-1214.

Ma, S., Sun, D., Simmons, J.M., Collier, C.D., Yuan, D., Zhou, H.-C., 2008. Metal-organic framework from an anthracene derivative containing nanoscopic cages exhibiting high methane uptake. Journal of the American Chemical Society 130, 1012-1016.

Ma, S., Zhou, H.-C., 2010. Gas storage in porous metal-organic frameworks for clean energy 
applications. Chemical Communications 46, 44-53.

Martin, M.G., Siepmann, J.I., 1998. Transferable potentials for phase equilibria. 1. United-atom description of n-alkanes. Journal of Physical Chemistry B 102, 2569-2577.

Mason, J.A., Veenstra, M., Long, J.R., 2014. Evaluating metal-organic frameworks for natural gas storage. Chemical Science 5, 32-51.

Mayo, S.L., Olafson, B.D., Goddard, W.A., 1990. DREIDING - A generic force-field for molecular simulations. Journal of Physical Chemistry 94, 8897-8909.

Millange, F., Serre, C., Férey, G., 2002. Synthesis, structure determination and properties of MIL-53as and MIL-53ht: the first $\mathrm{Cr}^{\mathrm{III}}$ hybrid inorganic-organic microporous solids: $\mathrm{Cr}^{\mathrm{III}}(\mathrm{OH}) \cdot\left\{\mathrm{O}_{2} \mathrm{C}-\mathrm{C}_{6} \mathrm{H}_{4}-\mathrm{CO}_{2}\right\} \cdot\left\{\mathrm{HO}_{2} \mathrm{C}-\mathrm{C}_{6} \mathrm{H}_{4}-\mathrm{CO}_{2} \mathrm{H}\right\}_{\mathrm{x}}$. Chemical Communications, 822-823.

Morris, R.E., Wheatley, P.S., 2008. Gas storage in nanoporous materials. Angewandte Chemie-International Edition 47, 4966-4981.

O'Keeffe, M., Peskov, M.A., Ramsden, S.J., Yaghi, O.M., 2008. The Reticular Chemistry Structure Resource (RCSR) Database of, and Symbols for, Crystal Nets. Accounts of Chemical Research 41, 1782-1789.

Peng, Y., Krungleviciute, V., Eryazici, I., Hupp, J.T., Farha, O.K., Yildirim, T., 2013. Methane Storage in Metal-Organic Frameworks: Current Records, Surprise Findings, and Challenges. Journal of the American Chemical Society 135, 11887-11894.

Plimpton, S., 1995. Fast parallel algorithms for short-range molecular-dynamics. Journal of Computational Physics 117, 1-19.

Rives, S., Jobic, H., Ragon, F., Devic, T., Serre, C., Ferey, G., Ollivier, J., Maurin, G., 2012. Diffusion of Long Chain n-alkanes in the Metal-Organic Frameowrk MIL-47(V): A Combination of Neutron Scattering Experiments and Molecular Dynamics Simulations. Microporous and Mesoporous Materials 164, 259-265.

Rosenbach, N.J., Jobic, H., Ghoufi, A., Devic, T., Koza, M.M., Ramsahye, N., Mota, C.J., Serre, C., Maurin, G., 2014. Diffusion of Light Hydrocarbons in Flexible MIL-53(Cr) Metal-Organic Framework: A Combination of Quasi-Elastic Neutron Scattering and Molecular Dynamics Simulation. Journal of Physical Chemistry C 118, 14471-14477.

Rowsell, J.L.C., Yaghi, O.M., 2004. Metal-organic frameworks: a new class of porous materials. Microporous and Mesoporous Materials 73, 3-14.

Sarkisov, L., Duren, T., Snurr, R.Q., 2004. Molecular Modelling of Adsorption in Novel Nanoporous Metal-Organic Materials. Molecular Physics 102, 211.

Sarkisov, L., Harrison, A., 2011. Computational structure characterisation tools in application to ordered and disordered porous materials. Molecular Simulation 37, 1248-1257.

Senkovska, I., Kaskel, S., 2008. High pressure methane adsorption in the metal-organic frameworks $\mathrm{Cu}_{3}(\mathrm{btc})_{2}, \quad \mathrm{Zn}_{2}(\text { bdc })_{2}$ dabco, and $\mathrm{Cr}_{3} \mathrm{~F}\left(\mathrm{H}_{2} \mathrm{O}\right)_{2} \mathrm{O}(\mathrm{bdc})_{3}$. Microporous and 
Mesoporous Materials 112, 108-115.

Stallmach, F., Groger, S., Kunzel, V., Karger, J., Yaghi, O.M., Hesse, M., Muller, U., 2006. NMR Studies on the Diffusion of Hydrocarbons on the Metal-Organic Framework Materials MOF-5. Angewandte Chemie-International Edition 45, 2123-2126.

Stoeck, U., Krause, S., Bon, V., Senkovska, I., Kaskel, S., 2012. A highly porous metal-organic framework, constructed from a cuboctahedral super-molecular building block, with exceptionally high methane uptake. Chemical Communications 48, 10841-10843.

Wang, X.-S., Ma, S., Rauch, K., Simmons, J.M., Yuan, D., Wang, X., Yildirim, T., Cole, W.C., Lopez, J.J., de Meijere, A., Zhou, H.-C., 2008. Metal-organic frameworks based on double-bond-coupled di-isophthalate linkers with high hydrogen and methane uptakes. Chemistry of Materials 20, 3145-3152.

Wilmer, C.E., Farha, O.K., Yildirim, T., Eryazici, I., Krungleviciute, V., Sarjeant, A.A., Snurr, R.Q., Hupp, J.T., 2013. Gram-scale, high-yield synthesis of a robust metal-organic framework for storing methane and other gases. Energy \& Environmental Science 6, $1158-1163$.

Wu, H., Simmons, J.M., Liu, Y., Brown, C.M., Wang, X.-S., Ma, S., Peterson, V.K., Southon, P.D., Kepert, C.J., Zhou, H.-C., Yildirim, T., Zhou, W., 2010. Metal-Organic Frameworks with Exceptionally High Methane Uptake: Where and How is Methane Stored? Chemistry-a European Journal 16, 5205-5214.

Wu, H., Zhou, W., Yildirim, T., 2009. High-Capacity Methane Storage in Metal-Organic Frameworks $\mathrm{M}_{2}$ (dhtp): The Important Role of Open Metal Sites. Journal of the American Chemical Society 131, 4995-5000.

Zhou, Z., Xue, C., Yang, Q., Zhong, C., 2009. Design of New Metal-organic Frameworks for Methane Storage. Acta Chimica Sinica 67, 477-482. 
Table 1. Geometrical properties of the MOFs computed using Poreblazer program.

\begin{tabular}{|c|c|c|c|}
\hline MOF & Density $\left(\mathrm{kg} / \mathrm{m}^{3}\right)$ & $\begin{array}{c}\text { Largest cavity } \\
\text { diameter, LCD }(\AA)\end{array}$ & $\begin{array}{c}\text { Pore limiting } \\
\text { diameter, PLD }(\AA)\end{array}$ \\
\hline PCN-14 & 828.91 & 10.84 & 4.29 \\
\hline NU-125 & 540.57 & 20.38 & 5.01 \\
\hline Py-4TT-ftw & 535.88 & 15.65 & 5.52 \\
\hline NU-1100 & 530.45 & 16.78 & 5.32 \\
\hline Py-4PT-ftw & 448.08 & 18.45 & 5.24 \\
\hline DUT-49 & 302.46 & 24.20 & 9.00 \\
\hline
\end{tabular}


Figure 1. (a) Organic linker of PCN-14, (b) Copper paddlewheel, the metal node in PCN-14, (c) The structure of PCN-14. Oxygen is red, carbon is grey, hydrogen is white and copper is pink in colour.

Figure 2. (a) Organic linker of NU-125, (b) Copper paddlewheel, the metal node in NU-125, and (c) The structure of NU-125. Nitrogen is blue in colour.

Figure 3. (a) Organic linker of DUT-49, (b) Cobalt paddlewheel, the metal node in DUT-49, and (c) The structure of DUT-49. Cobalt is light blue in colour.

Figure 4. (a) Organic linker of NU-1100, (b) $\mathrm{Zr}_{6}$ metal node in NU-1100, and (c) One unit cell of NU-1100. Zr is light green in colour.

Figure 5. Organic linkers in (a) Py-4PT-ftw and (b) Py-4TT-ftw. These are hypothetical MOFs and have the same metal node and structure as NU-1100.

Figure 6. Pore size distributions of the MOFs considered.

Figure 7. Self-diffusion coefficients as a function of loading for the pure components methane, ethane, propane and butane in PCN-14, NU-1100, Py-4PT-ftw and Py-4TT-ftw. The loading is described relative to the saturation loading $\left(\theta_{0}\right)$ of the respective components. The saturation loadings were obtained from the simulated adsorption isotherms shown in Figure S1.

Figure 8. Diffusivities as a function of loading for the pure components in NU-125 and DUT-49.

Figure 9. Different cages in (a) NU-125 and (b) DUT-49. The cages are shown with filled spheres of diameters corresponding to the cage diameters. The green spheres show the largest cavity, the yellow spheres show the second largest cavity, and the pink spheres indicate the smallest cavity in both MOFs. NU-125 has a fourth cage, which is almost comparable to the size of the smallest one, and this is indicated by the blue sphere. The cages are numbered 
with increasing numbers corresponding to increasing diameters.

Figure 10. Average number of propane molecules per cage in NU-125 and DUT-49 at low loading $\left(\theta / \theta_{0}=0.02\right)$ and high loading $\left(\theta / \theta_{0}=0.5\right)$.

Figure 11. Comparison of diffusivities of pure methane and methane in binary mixtures with ethane, propane and butane.

Figure 12. Comparison of diffusivities of the impurity components when they are pure and when they are in mixtures with methane. 


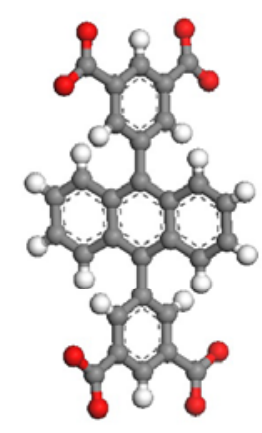

(a)

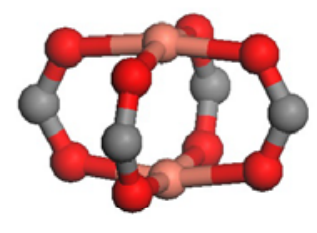

(b)

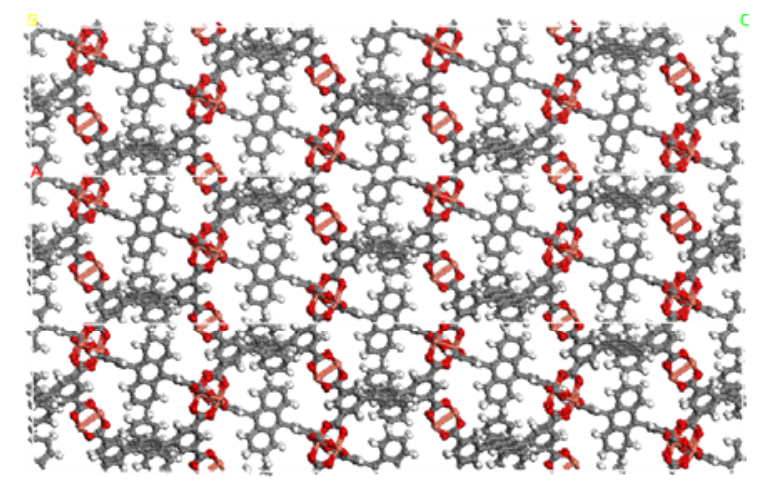

(c)

Figure 1 


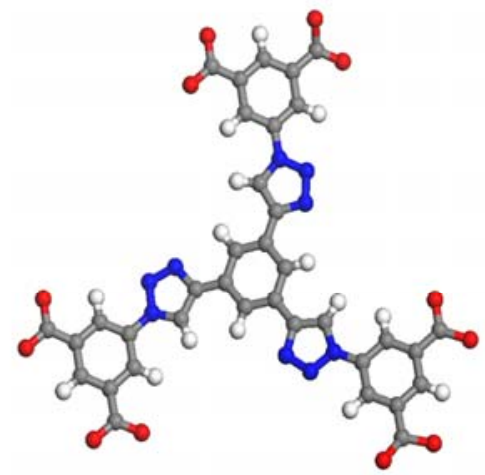

(a)

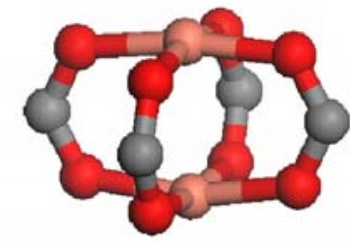

(b)

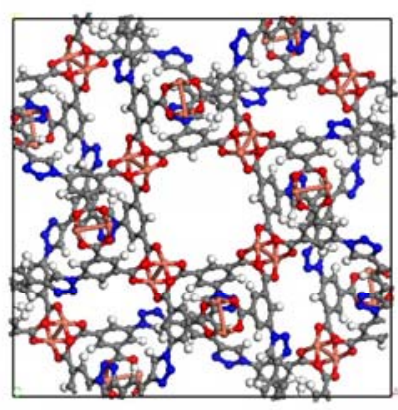

(c)

Figure 2 


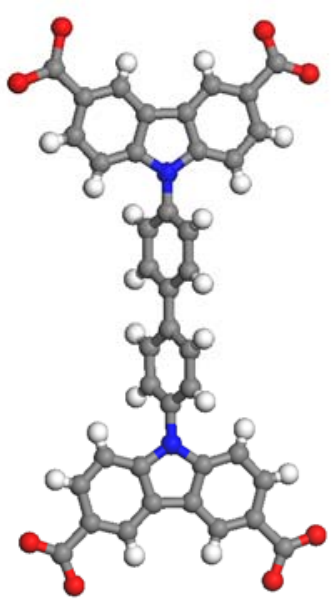

(a)

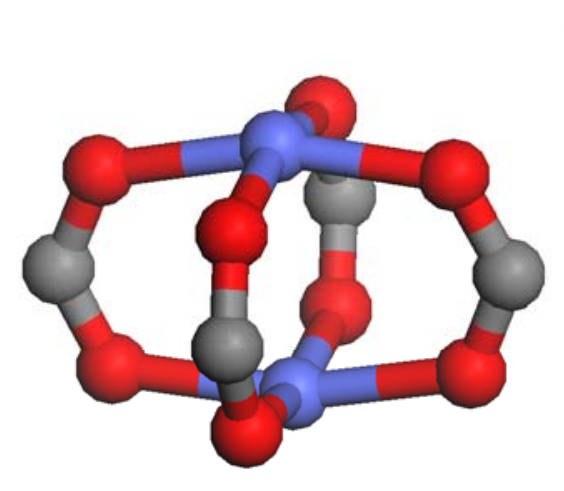

(b)

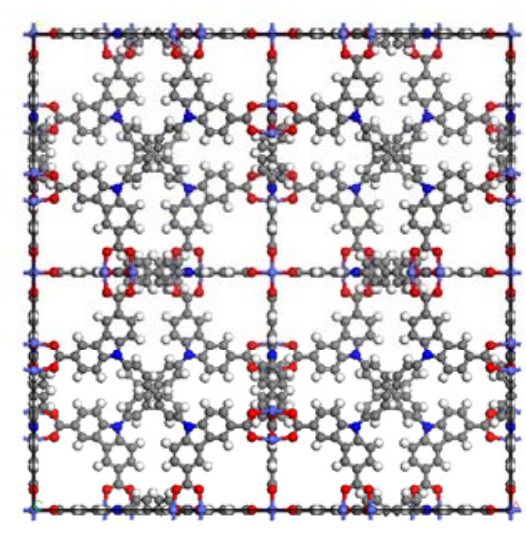

(c)

Figure 3 


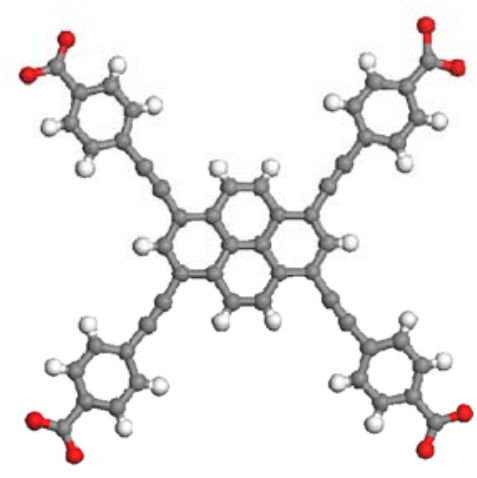

(a)

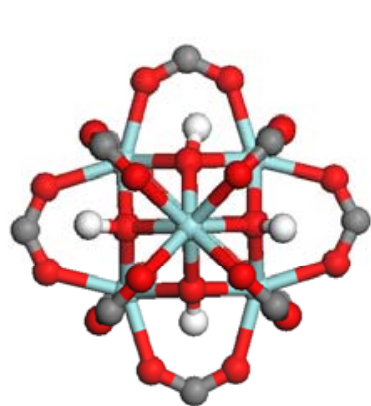

(b)

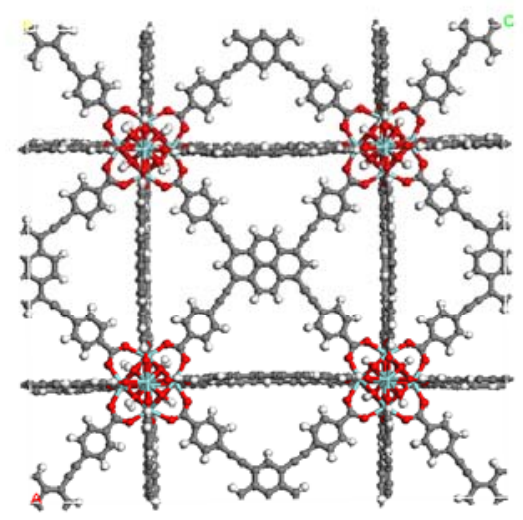

(c)

Figure 4 

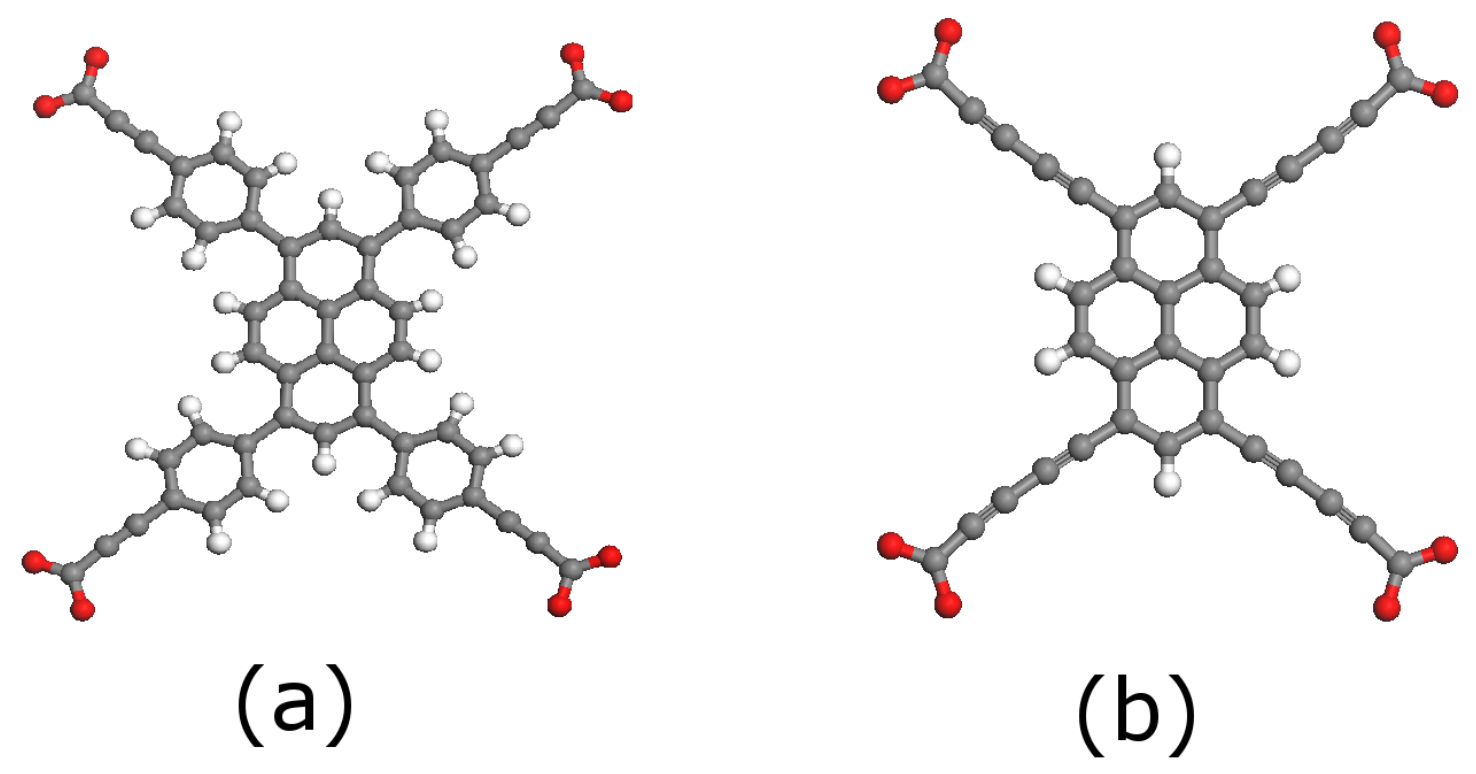

Figure 5 

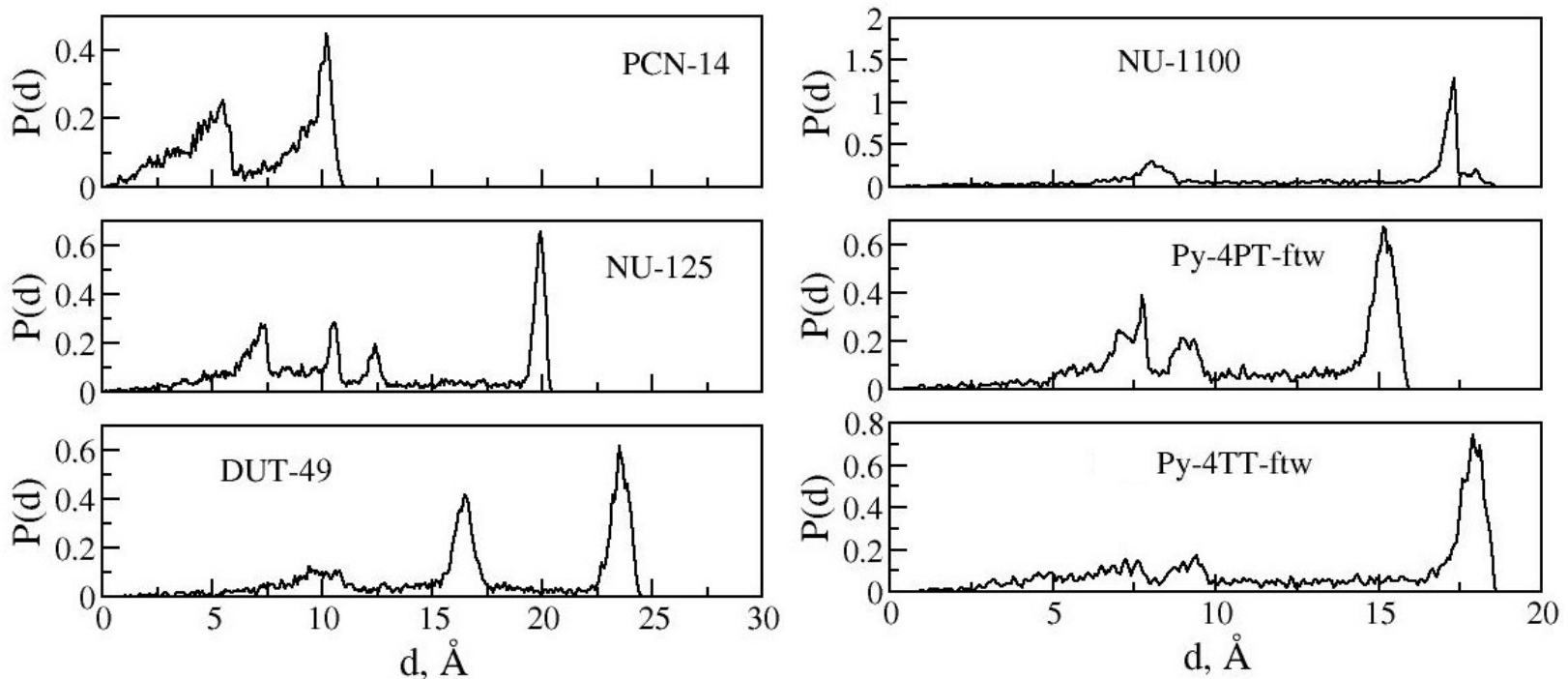

Figure 6 

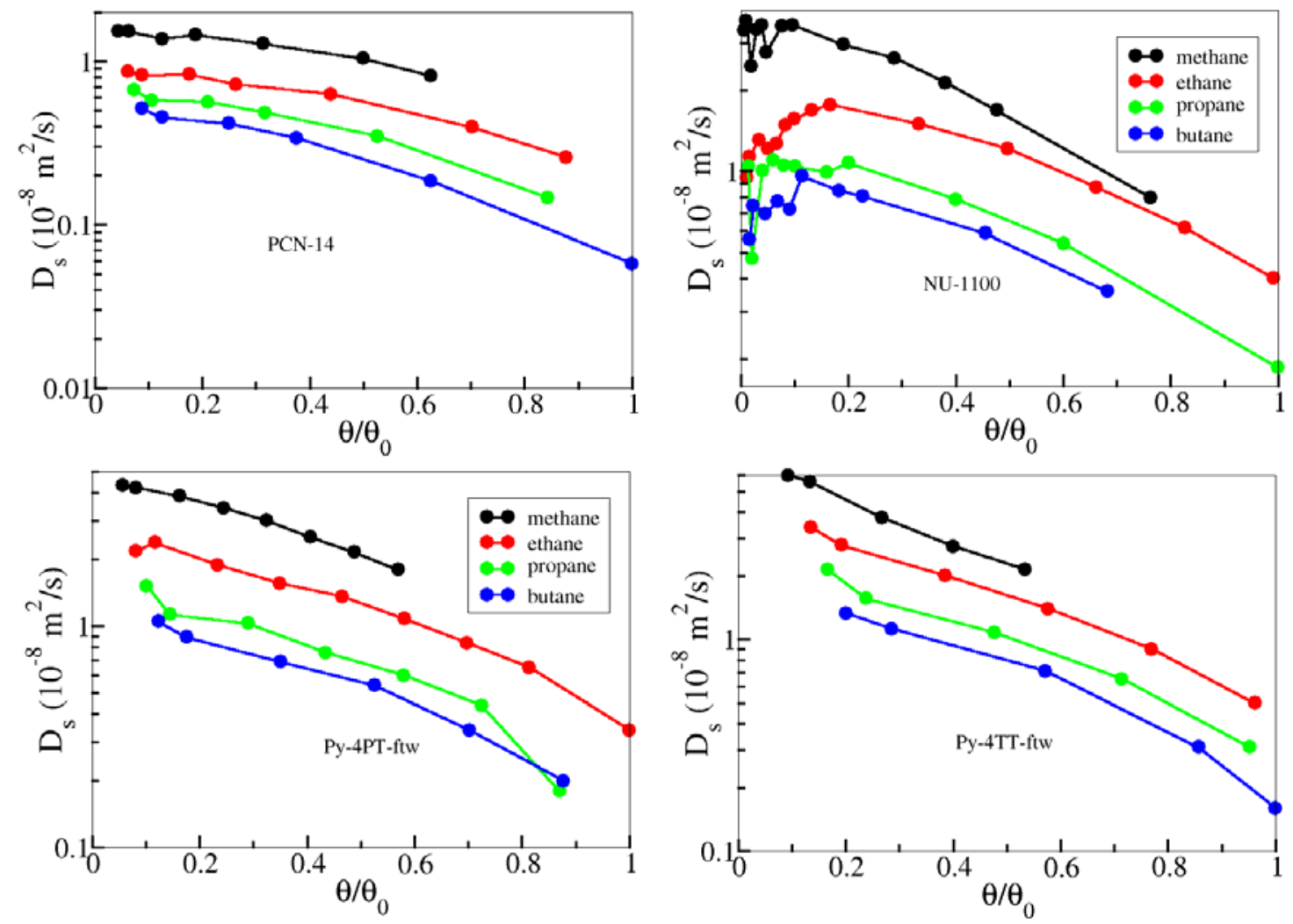

Figure 7 

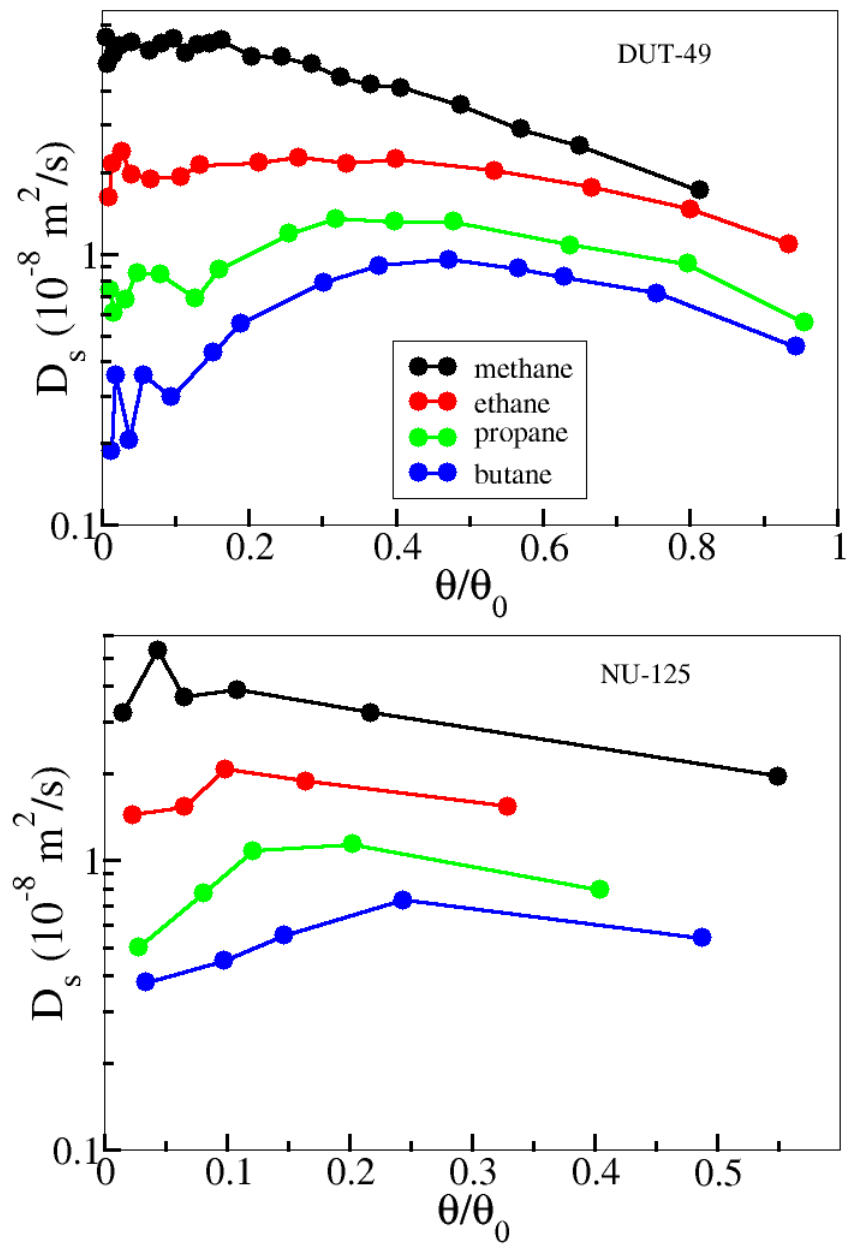

Figure 8 

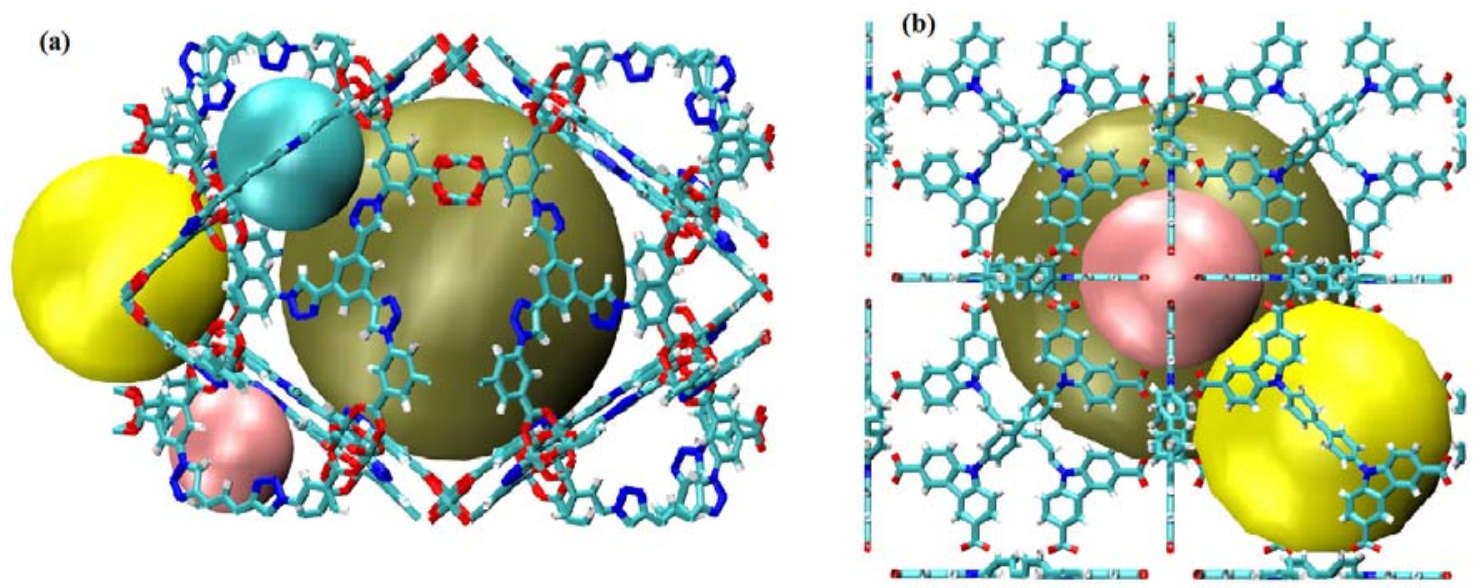

Figure 9 

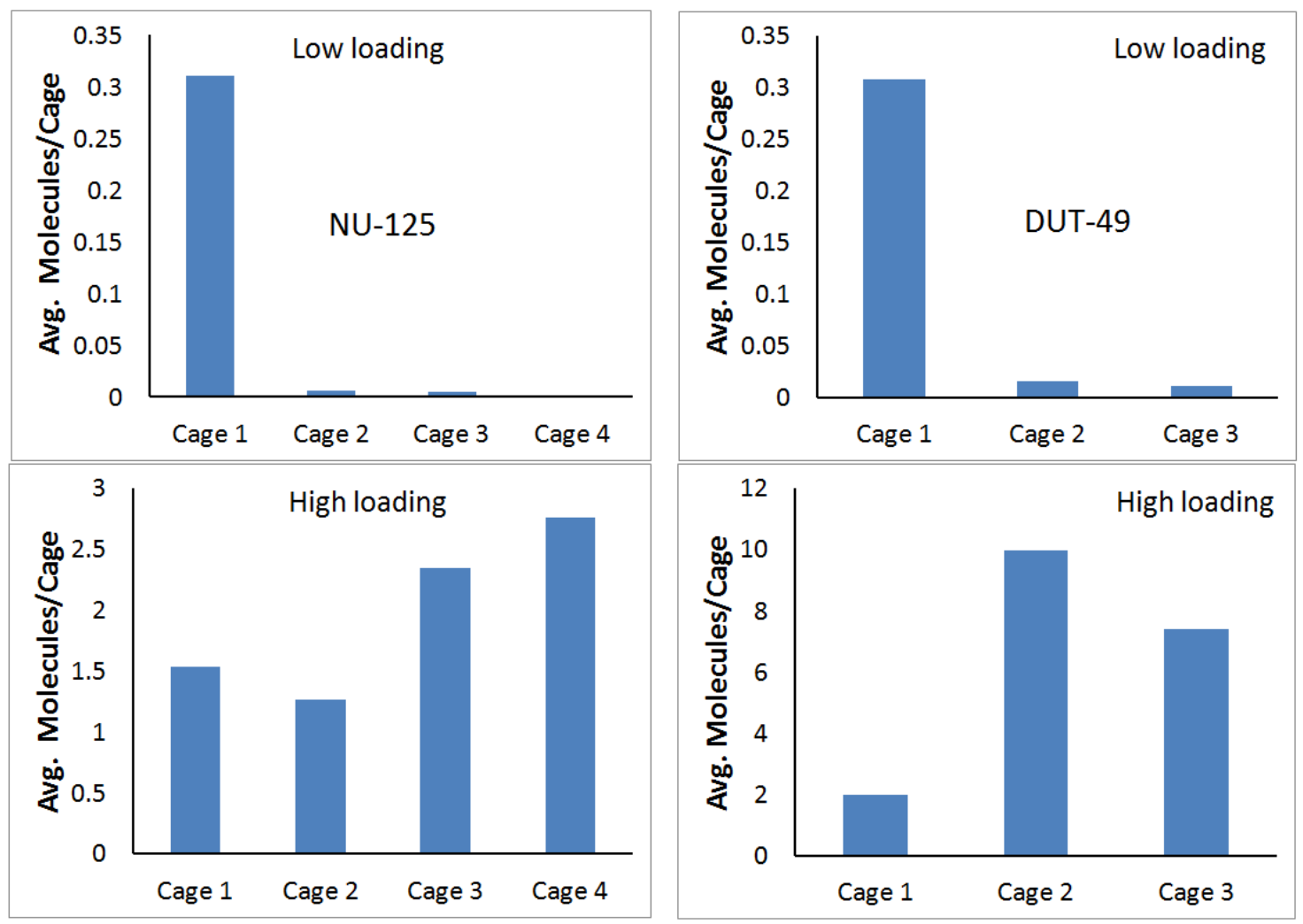

Figure 10 


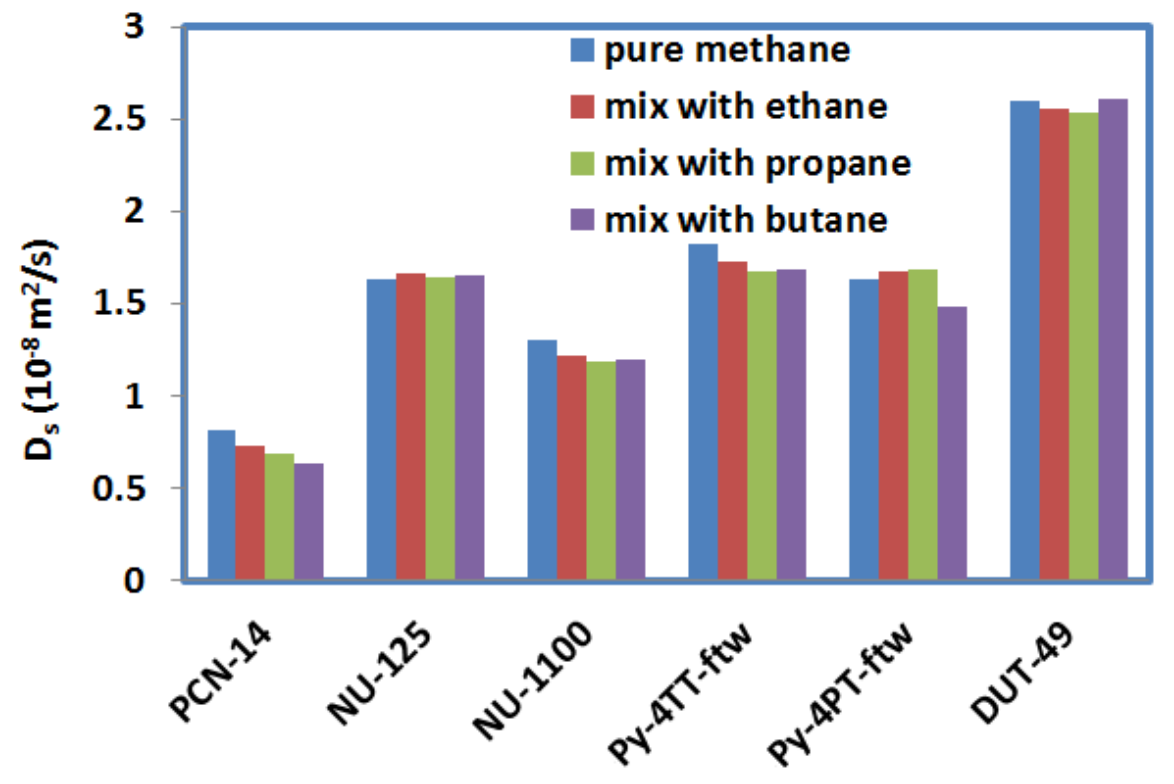

Figure 11 

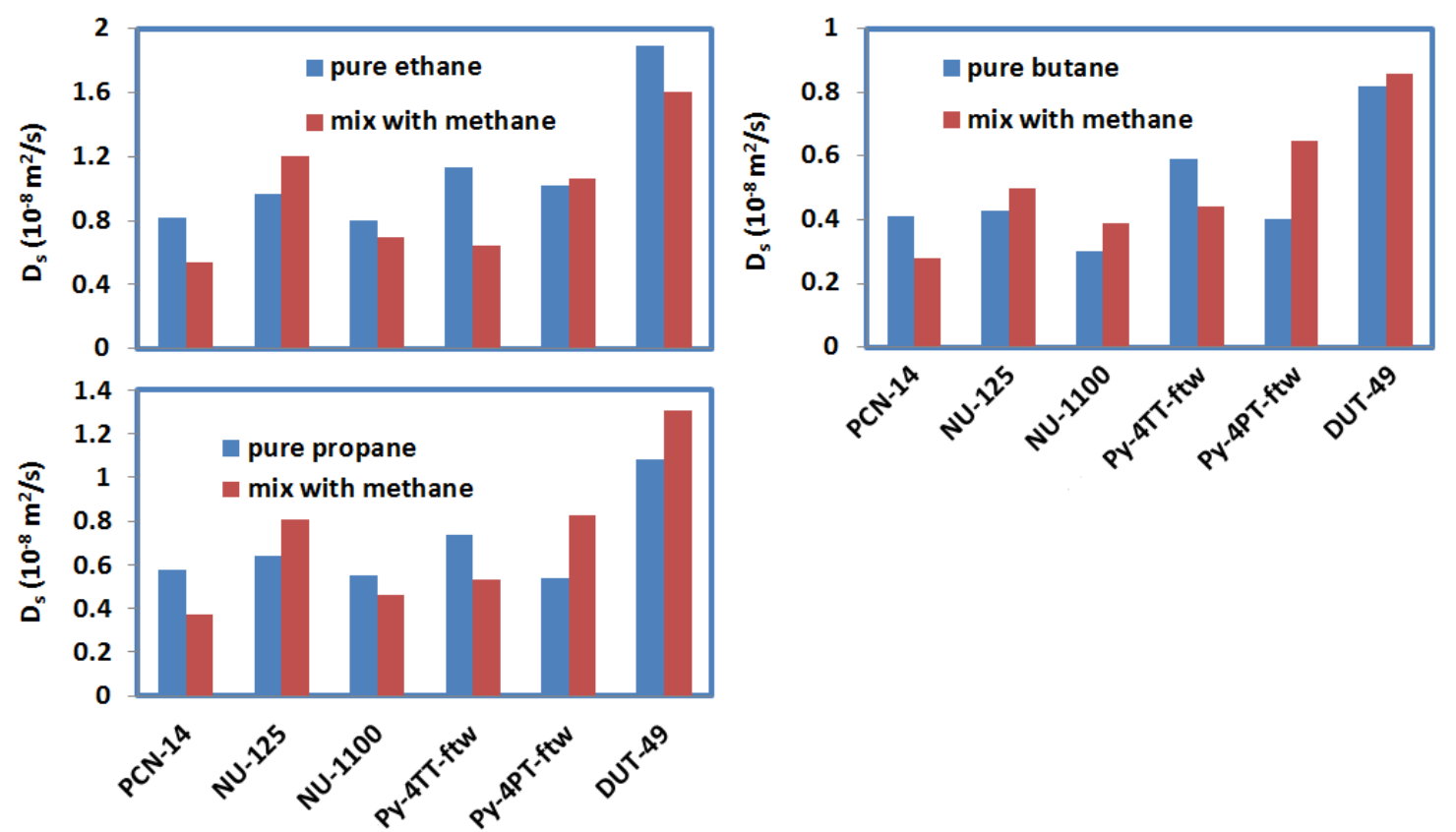

Figure 12 

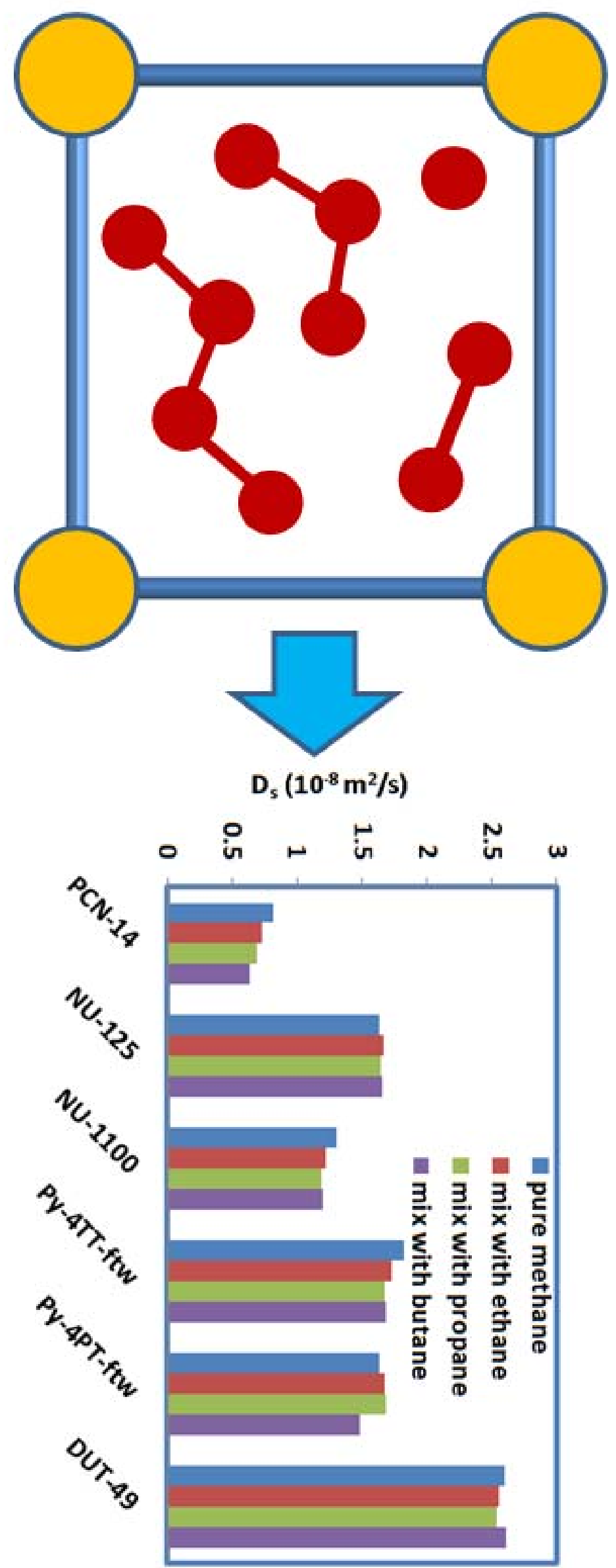